\title{
EXTRADOS STRENGTHENING OF SINGLE-LEAF VAULTS AGAINST SEISMIC ACTIONS
}

\author{
S. COMINELLI ${ }^{1}$, C. PASSONI ${ }^{2}$, A. MARINI ${ }^{2}$ A. BELLERI ${ }^{2}$, AND E. GIURIANI $^{1}$ \\ ${ }^{1}$ Dipartimento di Ingegneria Civile, Architettura, Territorio Ambiente e Matematica (DICATAM) \\ Università degli Studi di Brescia \\ Via Branze 43, 25123, Brescia (BS), Italy \\ e-mail: \{stefania.cominelli, ezio.giuriani\}@unibs.it, http://www.unibs.it \\ ${ }^{2}$ Dipartimento di Ingegneria e Scienze Applicate (DISA) \\ Università degli Studi di Bergamo \\ Viale Marconi 5, 24044, Dalmine (BG), Italy \\ e-mail: \{chiara.passoni, alessandra.marini, andrea.belleri\}@unibg.it, http://www.unibg.it \\ (*corresponding author)
}

Keywords: single-leaf vaults, seismic strengthening, direct bending, extrados techniques, plywood centering, FRP laminates

\begin{abstract}
Single-leaf vaults are acknowledged among the most vulnerable components of historical masonry constructions with respect to earthquake loads, particularly when featuring large span to thickness ratios, as in the case of single leaf covering the main nave of churches. These elements often require structural strengthening against seismic actions. In this paper, two different extrados techniques are tested: lightweight plywood restraining elements and FRP laminates embedded in a lime mortar layer. The techniques are tested on single leaf vaults having a very unfavorable span to thickness ratio.

A previous study on less slender vaults, showed that lightweight plywood centerings, applying passive confinement to the vault extrados, inhibit the onset of the typical four-hinges failure mechanism. This lightweight, dry solution can be easily prefabricated, transferred and assembled at the construction site. The technique is reversible and fully compliant with the major preservation principles. FRP is also effective against the onset of the failure mechanism but entails larger deformations of the retrofitted vault, which may be detrimental in the case of possible decorations. The solution requires special man labor to ensure correct smoothening and cleaning of the vault extrados and to trigger effective bond between the mortar and the vault extrados. Both solutions are shown to enable small relative displacements of the vault springing, which may follow the deformation of possible internal ties.

The effectiveness of these retrofit techniques was comparatively verified through experimental tests on single-leaf barrel vault stripes at 1:2 scale subjected to cyclic distributed unsymmetrical loads and through comparison with the seismic response of a reference unreinforced single-leaf vault.
\end{abstract}




\section{INTRODUCTION}

Single leaf vaults are thin vaults (about $50 \mathrm{~mm}$ thick) adopted in churches and historical buildings all over the European territory [1-3] as lightweight false ceilings, typically decorated with stuccos and frescoes. These elements, which are made of a single layer of bricks laid flat and usually lacking any extrados backfilling material and lunettes, are acknowledged among the most vulnerable components of historical masonry buildings with respect to earthquake loads, particularly when featuring quite large span to thickness ratios. Single leaf vaults may bridge spans ranging between 3 and $6 \mathrm{~m}$ in residential historical buildings and between 6 to $10 \mathrm{~m}$ in the main naves of churches.

Considering single-leaf barrel vaults lacking backfill material, equilibrium is guaranteed as long as the thrust line, associated with both static and seismic loads, develops within the vault thickness [4-8]. Unsymmetrical load distributions may be detrimental for these structures provided that the ideal resisting arch has a reduced possibility to shift and modify within such a reduced thickness. This problem could be emphasized in the case the vault has not a catenary geometry, but rather a circular geometry, in which case the thrust line in static conditions does not overlap the centroid axis. As a result, these structures are particularly vulnerable even for low-intensity earthquakes, as confirmed by the collapses observed after recent earthquakes [9].

As stated in [9-10], 3 mechanisms may be experienced by thin single-leaf vaults in the case of a seismic event: (a) indirect differential bending of the vault crown caused by the rotation of the vault springing due to the unconstrained rocking motion of the supporting wall (Fig. 1a);

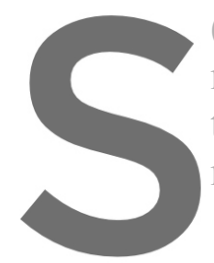
(b) severe shear distortion stresses and distorti
mechanism along the nave ends - usualy as a
the transverse arches (Fig. 1b); and (c) direct diff
mechanism due to the distributed seismic action

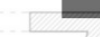
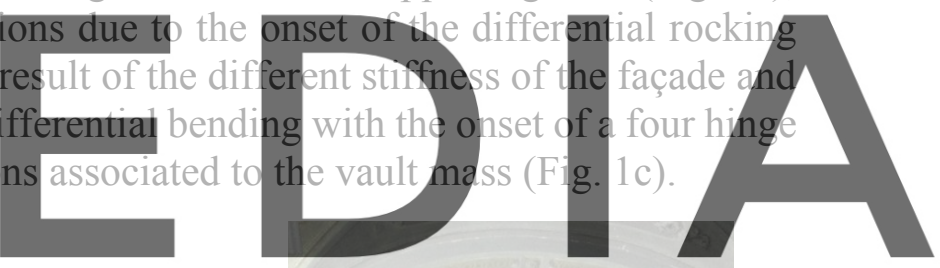

Register for free at https//www.scipedia.com to download the version without the watermark

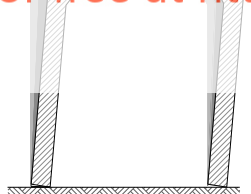

a)

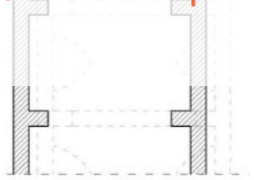

b)

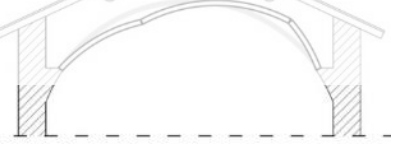

c)

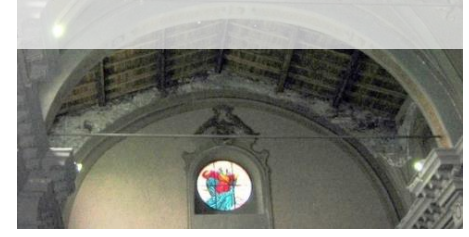

Figure 1: Main seismic vulnerabilities of single-leaf vaults: (a) indirect bending following rocking of the abutments; (b) shear distortion following differential rocking; (c) direct bending of the vault due to its own mass (from [17]). On the right: total collapse of the first bay (due to mechanism b) and partial collapse of the second bay (due to mechanism c) of the main nave of S.Pietro Church, Vobarno, Italy, after Salò earthquake, 2004 [9].

The two former mechanisms can be limited or inhibited through global interventions, such as either perimeter ties (mechanism a), or roof and floor diaphragms (mechanism a and b), which reduce the vault impost rotation and relative displacement [11]. On the contrary, the direct differential bending (mechanism c) cannot be inhibited, unless special targeted interventions are carried out on the structural element. Possible collapse induced by direct differential bending was addressed in a research carried out at the University of Brescia, in 
which a series of strengthening solutions were proposed and tested on full scale single-leaf vaults having 1/100 thickness to span ratio and a span of $5 \mathrm{~m}$ [12-17].

In the present paper, the study was extended to assess the effectiveness of some strengthening solutions in the case of thinner single-leaf vaults, with 1/200 thickness-to-span ratio, thus bridging larger spans up to $10 \mathrm{~m}$. Two different extrados techniques were proposed, namely: lightweight plywood restraining elements, and FRP laminates embedded in a lime mortar layer. To this end, 1:2 scaled single-leaf barrel vault stripes subjected to cyclic distributed unsymmetrical loads were tested. Results were compared with the seismic response of a reference unreinforced single-leaf vault.

\section{STRENGTHENING TECHNIQUES INHIBITING DIRECT DIFFERENTIAL BENDING MECHANISM}

The strengthening of single leaf barrel vaults with respect to direct differential bending mechanism usually adopts techniques derived from the traditional strengthening of masonry vaults, selecting those which do not increase the vault mass and avoiding unsymmetrical load sets [12]. The most common techniques entail the adoption of masonry spandrel walls [18] [10] [12-13], RC extrados slabs, or high-performance lime mortar extrados slabs strengthened with fiber mesh [12-13]. The former solution constrains the deformation of the vault crown and allows the thrust line to migrate within the spandrel wall height. The latter techniques enforce a composite structure behavior, allowing the ideal resisting arch to adjust within a higher thickness, but increases the mass of the vault and, more importantiy, in seismic conditions, the migration of the thrust of debonding and unthreacting ribs overlaying the vault grids and of an inner po Extrados stiff lightr
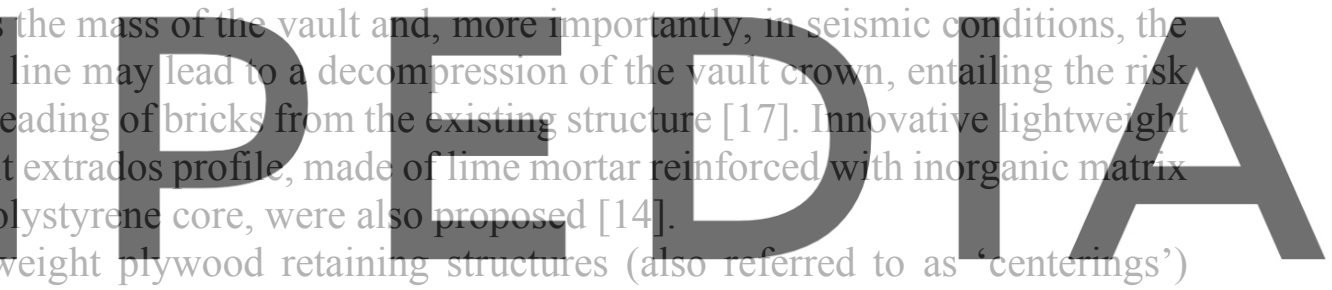
simply overlaying and not connected to the existing vault were also proposed [16-17]. The

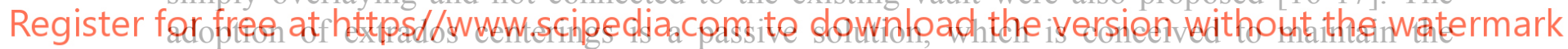

structural role of the vault in static conditions and to provide the necessary passive confinement in seismic conditions (Fig. 2 left). The system is designed as a 3-hinged arch overlaying the existing vault extrados, hinged at the abutments and with an internal hinge at the vault key section (Fig. 2 right). Connections along the centering-to-vault interface are avoided as to prevent the decompression of the vault. This is a lightweight, dry and cost-effective solution, fully reversible, minimally impairing, and not requiring any special man labor. The effectiveness of the system against direct differential bending was verified on single-leaf vaults having 1/100 thickness-to-span ratio [16-17]; in the tests, the collapse mechanism was inhibited for accelerations up to 4 times those causing the collapse of the unreinforced vault, and the stiffness of the vault was increased.

The use of fiber-reinforced polymer (FRP) strips is another efficient solution [19]. In this case, failure of the strengthened structure may arise due to possible shear failure close to the springing, as the technique enhances the sole bending capacity, or due to delamination of the FRP strips, triggered either by the uneven surface of the vault or by failure of the bond between the vault and the laminate. In order to solve durability issues and decay processes due to loss of transpiration potential, steel-reinforced grouts (SRG) [20], or inorganic matrix grids (IMG) 
embedded in lime-based mortar are alternative techniques [21-22]. In the present study, FRP laminates embedded in a lime mortar layer were considered.
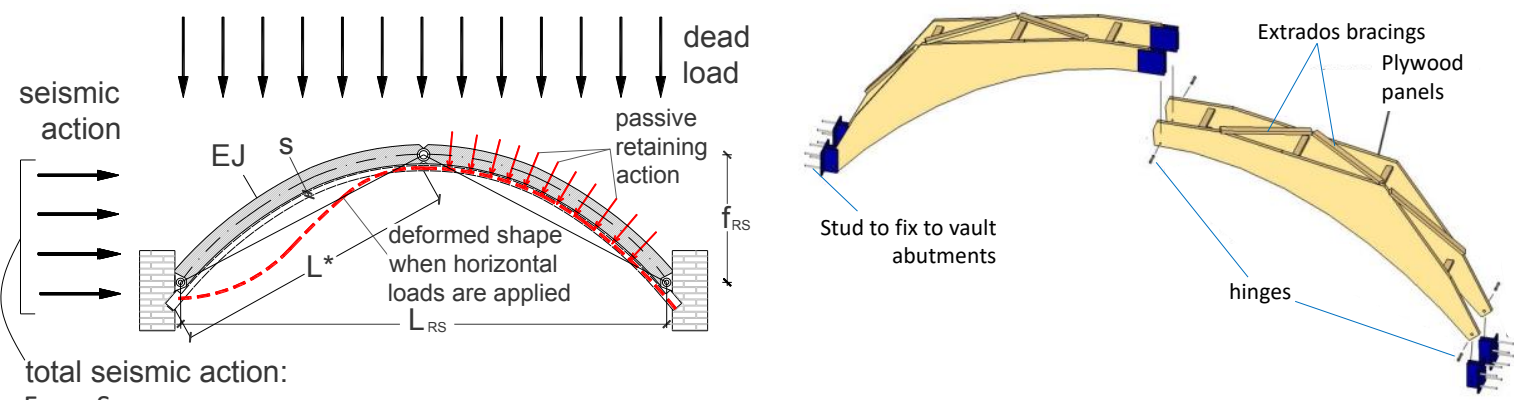

total seismic action:

$\mathrm{F}_{\mathrm{s}}=\mathrm{mvSad}$

Figure 2: Confining action of the plywood centering in case of earthquake (left) and details of the centering components and of the hinge location (right) [17]

\section{EXPERIMENTAL TESTS}

The experimental campaign was aimed at assessing the effectiveness of lightweight plywood centerings and FRP laminates for single-leaf vaults with very unfavorable thickness-to-span ratio (1/200) and was inspired by the campaign carried out at the University of Brescia on medium-span single-leaf vaults (1/100) [15-17]. The same testing bench was adopted, and the thickness of the vault was redueed to resemble a $50 \mathrm{~mm}$ vault bridging about $10 \mathrm{~m}$ span.

\subsection{Modelling hypothesis}

According to the preyious transversal adjoining vault st ip
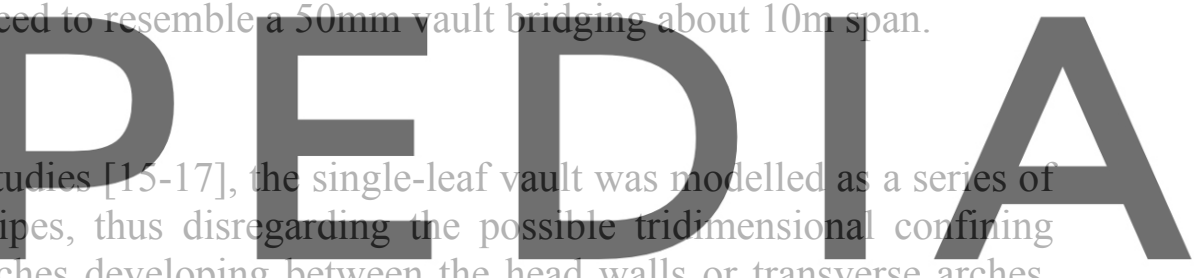

effects due the longitudinal arches developing between the head walls or transverse arches,

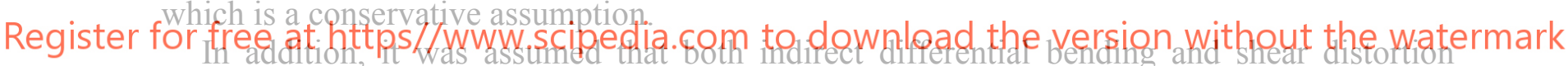
(mechanism a and b of Fig. 1) are inhibited through global interventions; so, it is considered that the vault is affected by the sole direct differential bending (mechanism $\mathrm{c}$ of Fig. 1).

Based on these two assumptions, a single barrel vault stripe of unit width was modelled in the experimental specimen, and the vault springing were assumed as fixed to the testing bench.

\subsection{Description of the unreinforced experimental specimen}

The experimental masonry vault specimen is a basic single-leaf barrel vault stripe of unit width at a scale $1: 2$ with a polycentric profile ( $\operatorname{span} \mathrm{L}=5 \mathrm{~m}$, rise $\mathrm{f}=1.42 \mathrm{~m}$, thickness $\mathrm{t}=27 \mathrm{~mm}$ ) (Fig. 3), thus representing a real vault of span $\mathrm{L}=10 \mathrm{~m}$, rise $\mathrm{f}=2.84 \mathrm{~m}$ and thickness $\mathrm{t}=54 \mathrm{~mm}$.

A flat brick arrangement with a running bond masonry texture was adopted; the ultimate capacity of possible plastic hinges is thus associated with the tensile resistance of the joints. The vault stripe is embedded at the springing and pre-stressing clamps and anchoring bars were installed to fix the vault abutments to the testing bench.

Mechanical properties of the adopted bricks and mortar (7.5\% NHL 3.5, 8.5\% lime putty, $34 \% 1.5 \mathrm{~mm}$ aggregates, $34 \% 3.0 \mathrm{~mm}$ aggregates, $16 \% \mathrm{H}_{2} \mathrm{O}$ ) are reported in Table 1 . 
Table 1: Average mechanical properties of bricks and mortar

\begin{tabular}{cc}
\hline Solid Clay Bricks (27x120x250mm) & Mortar (bed joints 7-8mm) \\
\hline Compressive strength: $2.245 \mathrm{MPa}$ & Compressive strength: $0.337 \mathrm{MPa}$ \\
\hline Flexural strength: $4.79 \mathrm{MPa}$ & Flexural strength: $0.180 \mathrm{MPa}$ \\
\hline Young's modulus: $10883.26 \mathrm{MPa}$ & Flexural strength (joint): $0.328 \mathrm{MPa}$ \\
\hline
\end{tabular}

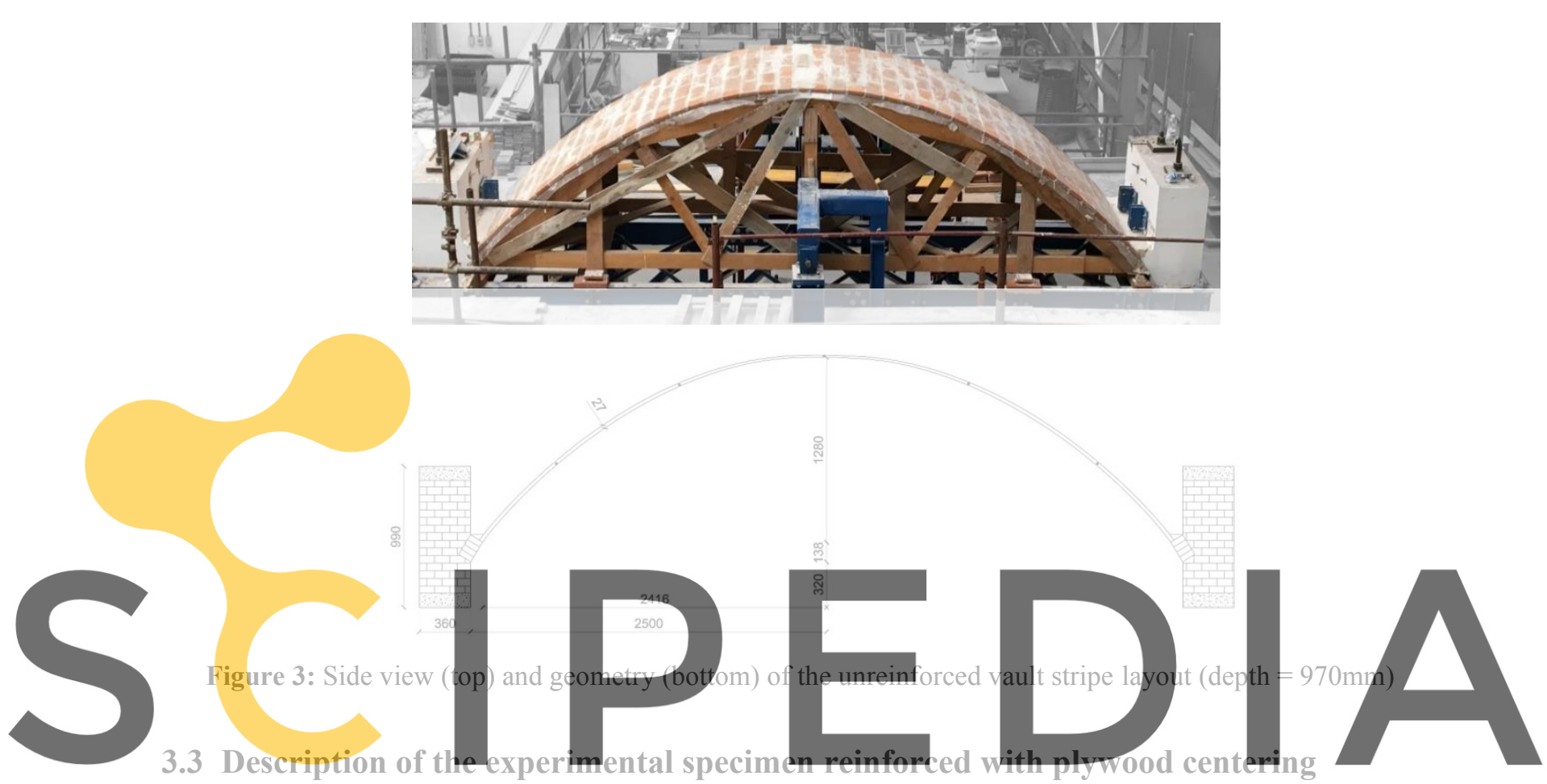

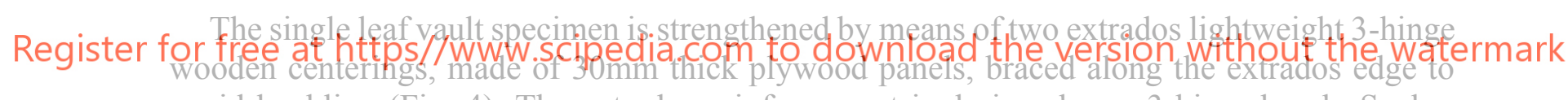

avoid buckling (Fig. 4). The extrados reinforcement is designed as a 3-hinged arch. Such a structural scheme enables small relative displacements of the vault springing, which may follow the deformation of the possible internal ties or of the roof box structure. The effectiveness of the system, both in the case of fixed supports and of a possible horizontal settlement of the vault abutments, was studied in a previous research [17].

The centering physical hinges at the springing and at the vault key are located as close as possible to the centering-to-vault extrados interface, as to reduce the offset of the vault centroid axis with respect to the centering. This reduces the relative displacements of the two structures both in the case of unsymmetrical load conditions (such as in the case of an earthquake) and in the case of spreading supports. No shear transfer is allowed along the vault-to-centering interface, whilst initial contact between the centering and the vault is enforced through thin wooden wedges. More about the design of the strengthening intervention in terms of flexural stiffness of the plywood centering may be found in [17].

Two tests were carried out on this specimen. In the first test, the wooden wedges were positioned between the vault and the centering and were simply glued to the vault, to enable a passive confining action; in the second test, the wedges were forced in correspondence of the 
vault-to-centering interface and were fixed in that position, thus leading to an active confining intervention. The results of both the tests are reported and commented in the following.
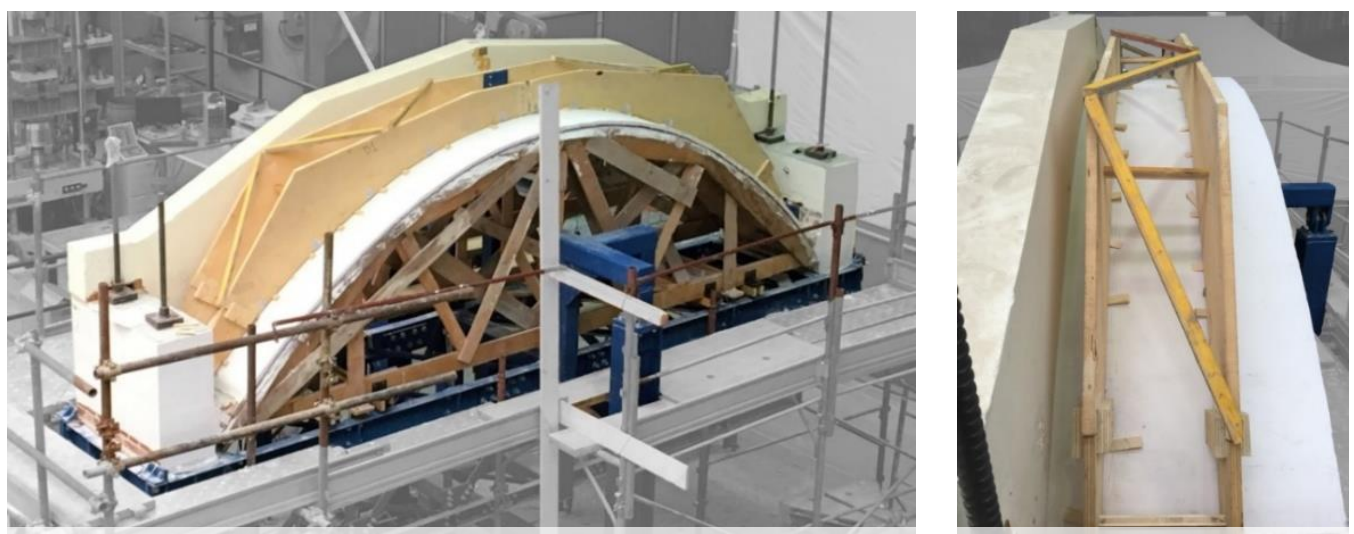

Figure 4: Side and top view of the vault stripe reinforced with the plywood centering

\subsection{Description of the experimental specimen reinforced with FRP laminates}

The single leaf vault specimen is strengthened by means of FRP laminates embedded in a pozzolanic hydraulic lime mortar layer (Fig. 5 left). The choice of an inorganic matrix was aimed at improving the transpiration potential of the retrofit intervention with respect to a

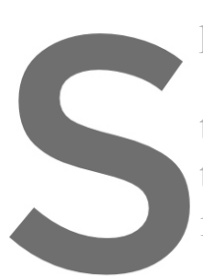
polymer matrix, for the sake of durability

A first layer of $3-4$ the carbon fiber mesh was

thickness (Fig. 5 right). The mechanical pro in Table 2

\section{int}
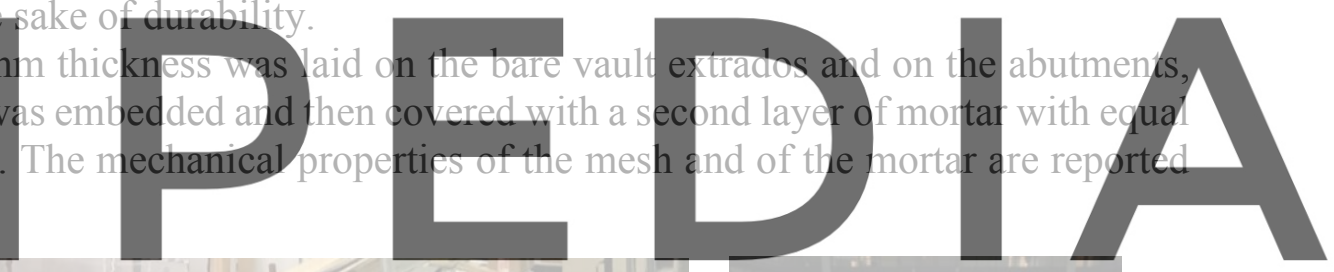

Register for free at https//www.scipedia.com to download the version without the watermark
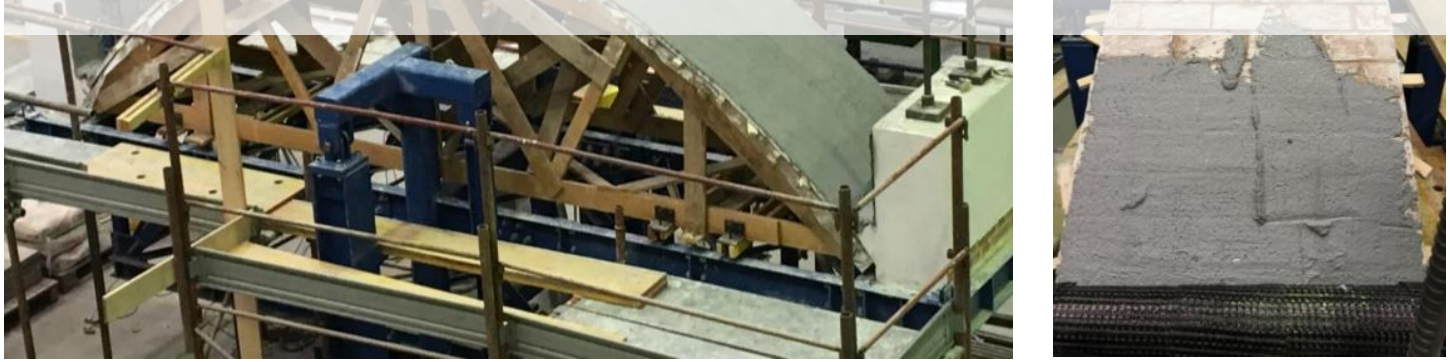

Figure 5: Side view of the vault stripe reinforced with the FRP laminates before the test (left) and top view of the vault during the strengthening operations (right)

Table 2: Average mechanical properties of carbon fiber grid and mortar

\begin{tabular}{cc}
\hline Carbon fiber mesh & Mortar matrix \\
\hline Ultimate tensile strength: $4830 \mathrm{MPa}$ & Compressive strength: $20.98 \mathrm{MPa}$ \\
\hline Elongation at break: $1.9 \%$ & Flexural strength: $4.83 \mathrm{MPa}$ \\
\hline Young's modulus: $240000 \mathrm{MPa}$ & Young's modulus: $10633 \mathrm{MPa}$ \\
\hline
\end{tabular}




\subsection{Test set-up}

The same test set-up proposed in [15-17] was adopted. The single leaf vault strip was assembled on a special swinging steel frame (Fig. 6a). By swinging the testing frame, increasing uniformly distributed inertia forces are applied along the vault crown. Rotation, and thus inertia forces, can be increased either up to failure of the specimen or up to the maximum rotation capacity of the testing bench. Dynamic effects cannot be considered.

The testing bench is composed by a rigid steel deck rotating both clockwise and counterclockwise about a pivot point A on a vertical frame fixed to the ground. The deck rotation is applied through a mechanical transmission system, actuated by an electromechanical jack (Fig. $6 a)$.

By assuming local reference fixed to the deck, the rotation of the specimen due to the swinging of the testing bench causes the gravity acceleration to decompose into one component parallel (horizontal, $\mathrm{a}_{\mathrm{x}}(\theta)$ ) and into a component orthogonal (vertical, $\mathrm{a}_{\mathrm{y}}(\theta)$ ) to the deck. For increasing the tilting angle $(\theta)$ from 0 to $30^{\circ}, a_{x}(\theta)$ increases, simulating earthquakes of increasing intensity; on the other hand, ay $(\theta)$ slightly reduces, thus simulating a reduction of the vertical load in static conditions ranging between 0 and $13.4 \%$. The horizontal-to-vertical spectral ratio $\alpha(\theta)=a_{x}(\theta) / a_{y}(\theta)$ can be easily determined (box in Fig. 6).

During all tests, the vault ring differential deflection was monitored in five points through vertical and horizontal displacement transducers, pinned to the vault mid axis and to a rigid polystyrene arch fixed to the abutments (Fig. 6b). The deck tilting angle was monitored by two
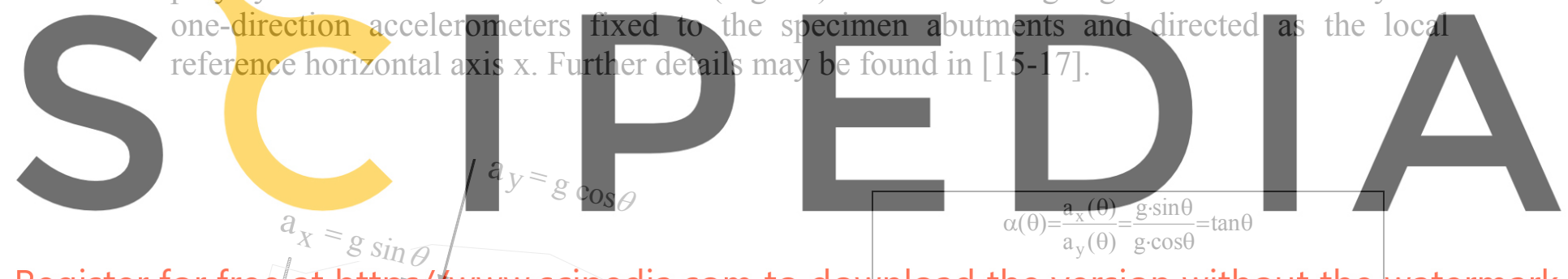

Register for free at https/\%www.scipedia.com to download the 3 versionfwithoukt the watermark

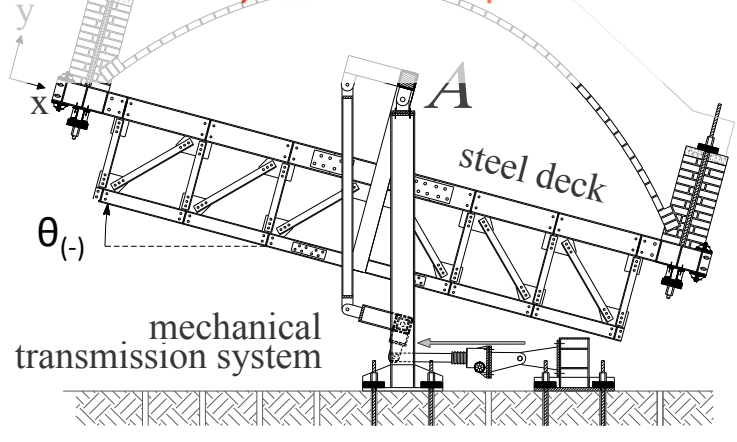

a)

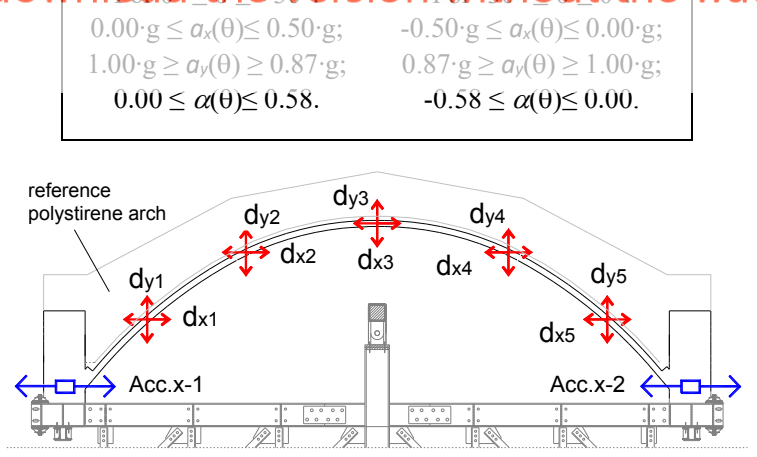

b)

Figure 6: a) Side view of the swinging testing frame in the tilted position (in the box: clockwise and counterclockwise maximum rotations and corresponding extreme values of relative accelerations and horizontal-tovertical acceleration ratio); b) instruments set-up: red arrows represent displacement transducers $\left(d_{x}, d_{y}\right)$ and blue arrows represent accelerometers (Acc.x) [17]. 


\section{EXPERIMENTAL TEST RESULTS AND DISCUSSION}

Four experimental tests were carried out. In the first test (Test 0 ), the tilting angles corresponding to the first cracking and to the collapse of the unreinforced vault were determined as reference values. Only counter-clockwise rotations were imposed to the specimen in order to avoid damage on both sides of the vault crown. The test was stopped at the tilting angle corresponding to the collapse of the vault (Fig 7a). Three tests on the reinforced vault were then carried out: two tests on the vault reinforced by means of plywood centerings with unforced (Test 1a) and forced (Test 1b) wooden wedges; and a test on the vault strengthened with FRP laminates (Test 2). Applied rotation cycles are shown in Fig. 7. All tests were interrupted for overcoming the rotation capacity of the testing frame $\left(\theta=30^{\circ}\right)$, corresponding to an $\mathrm{a}_{\mathrm{x}}(\theta)$ of about $0.50 \mathrm{~g}$ and $\alpha(\theta)$ of about 0.58 .
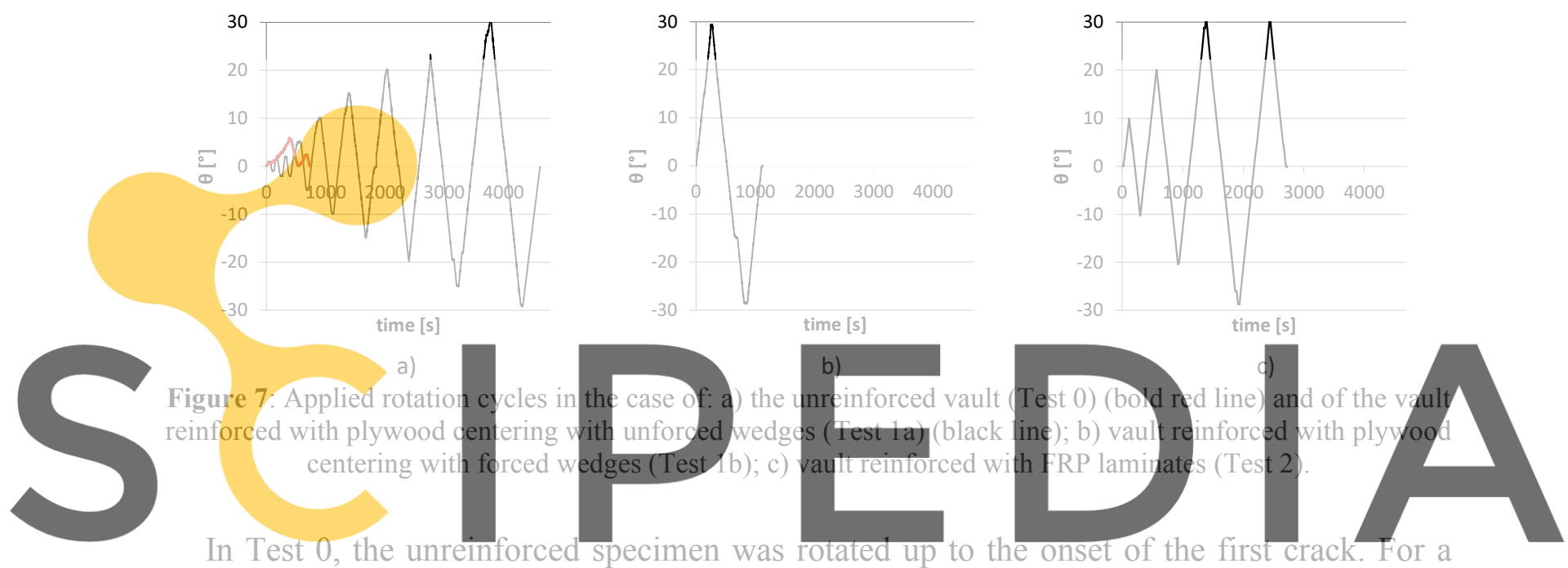
tilting angle $\theta=5.8^{\circ}$ (corresponding to $\alpha=0.105$ ), the windward vault segment collapsed leaning

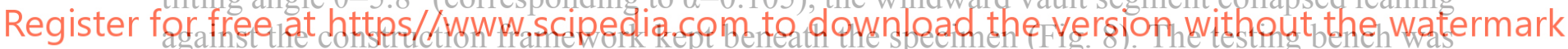

then brought back to the horizontal position, and the vault restored the initial uncracked configuration. In a second cycie, the tiliting angle was increased up to a second coliapse of the vault. This time, the unreinforced vault collapsed for a tilting angle $\theta=2.4^{\circ}$, lower than that experienced in the previous cycle, since the specimen was already damaged. The ultimate horizontal-to-vertical spectral ratio was thus considered $\alpha=0.044$ for the damaged vault.
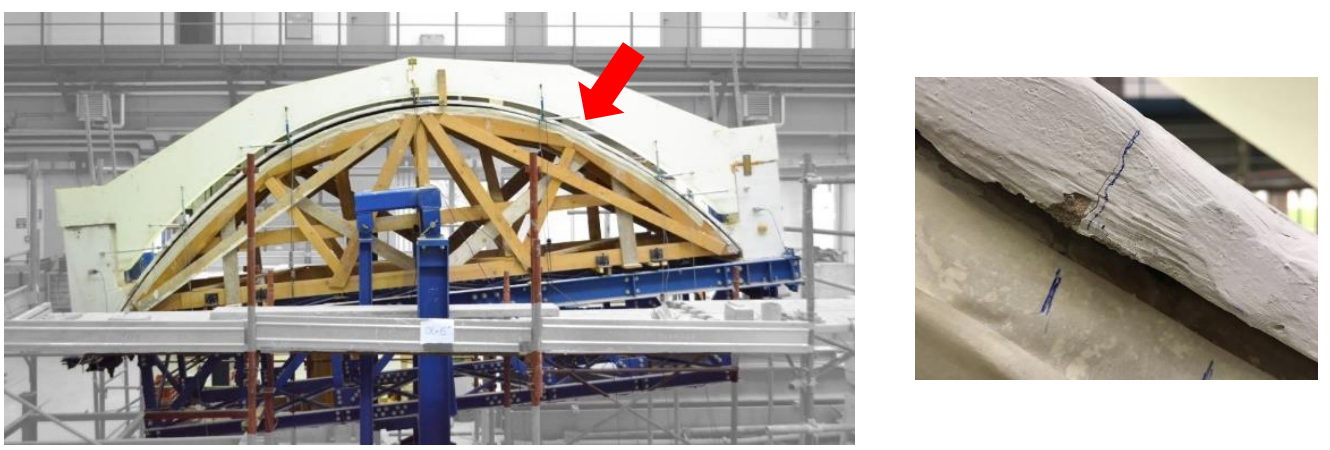

Figure 8: Side view of the vault for a counter-clockwise rotation $\theta=5.8^{\circ}$, corresponding to the first collapse. The red arrow and the figure on the right show the vault leaning against the construction framework. 
In the second phase of the experimental campaign, the vault was reinforced without repairing the cracking triggered during Test 0 , so as to be representative of a damaged existing vault.

The vault was first reinforced by means of plywood centerings with unforced wooden wedges ensuring contact at the vault-to-centering interface. In this first test (Test 1a), the vault did not collapse even for tilting angles up to $\pm 30^{\circ}$ (Fig. 9 left); however, deformations higher than expected were recorded. Two corrective measures were thus applied as to reduce the vault deformations (Test 1b): the wooden wedges at the vault-to-centering interface were forced as to simulate an active strengthening intervention, and an additional restraint was positioned at the centering ends as to limit possible vertical movements of the hinges. In this case, substantially smaller vertical displacements of the reinforced vaults were observed (Fig. 10). In both cases, the effectiveness of the plywood centerings in constraining the upward vertical displacement was verified.

Finally, the vault was reinforced by means of FRP laminates embedded in the lime mortar layer (Test 2). In this case, a crack opened in correspondence of the measuring point 2 (Fig. 6b) for a tilting angle $\theta=25.9^{\circ}$; however, collapse of the vault was not triggered even for tilting angles up to the testing bench capacity $\pm 30^{\circ}$.

A side view of the vault strengthened with plywood centerings and FRP laminates in correspondence of a counter-clockwise rotation equal to $30^{\circ}$ is shown in Fig. 9.
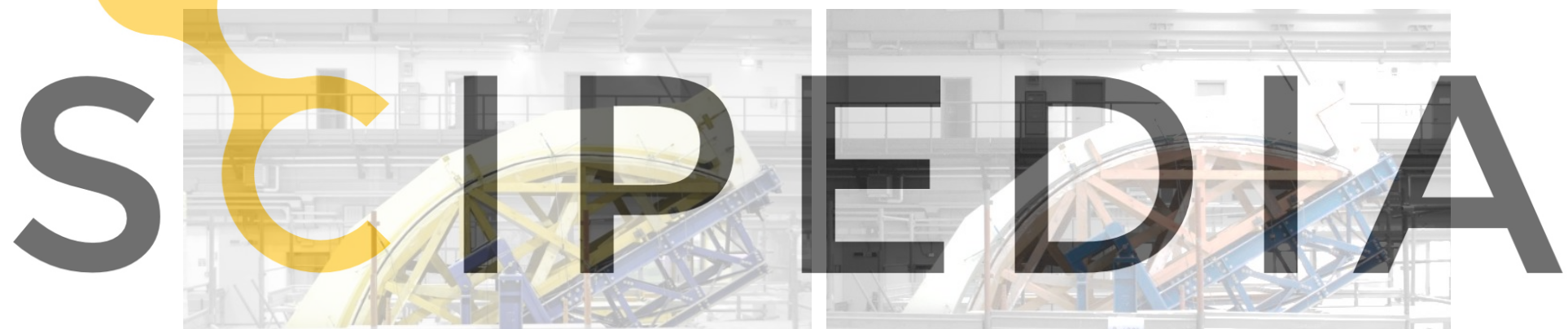

Register for free at https//www.scipedia.com to download the version without the watermark

Figure 9: Side view of the vault for a counter-clockwise rotation $\theta=30^{\circ}$, corresponding to the rotation capacity of testing bench, for the vault strengthened with plywood centerings (left) and FRP laminates (right)

The deformed shape of the vault in the unreinforced condition is compared to the deformed shape for a counter-clockwise rotation of $30^{\circ}$ in Figure 10a. Figure 10b shows the comparison of the deformed shapes of the vaults retrofitted with the three different strengthening solutions for a tilting angle equal to a counter-clockwise rotation of $30^{\circ}$. Deformations are magnified by a factor of 20. It should be noted that in Test $1 \mathrm{~b}$, the undeformed shape of the vault shown in the figure is not representative of the actual initial shape of the vault since the forcing operation of the wooding wedges was neither perfectly homogeneous nor symmetric along the vault extrados.

In all tests, for increasing rotation, the leeward part of the vault moves upward whereas the windward part moves downward. In case of centering strengthening, the leeward part of the vault pushes on the centering whereas the windward part may detach from it, thus leading to higher displacements in the windward part with respect to the leeward one. Displacements of 
the retrofitted vault are quite small even in correspondence of tilting angles approaching the rotation capacity of the testing frame. In the case of FRP strengthening, the behavior is similar meaning that the deformed shape shows the windward vault segment moving downwards, and the leeward segment moving upwards, but, in this case, larger displacements are observed with respect to the case of centering strengthening.

All the proposed techniques are proved to be effective solutions in improving the seismic response of the single leaf vault. However, the compatibility of the higher deformations exhibited by the vault strengthened with FRP laminates with the conservation of possible frescoes or stuccos on the vault intrados needs to be verified.

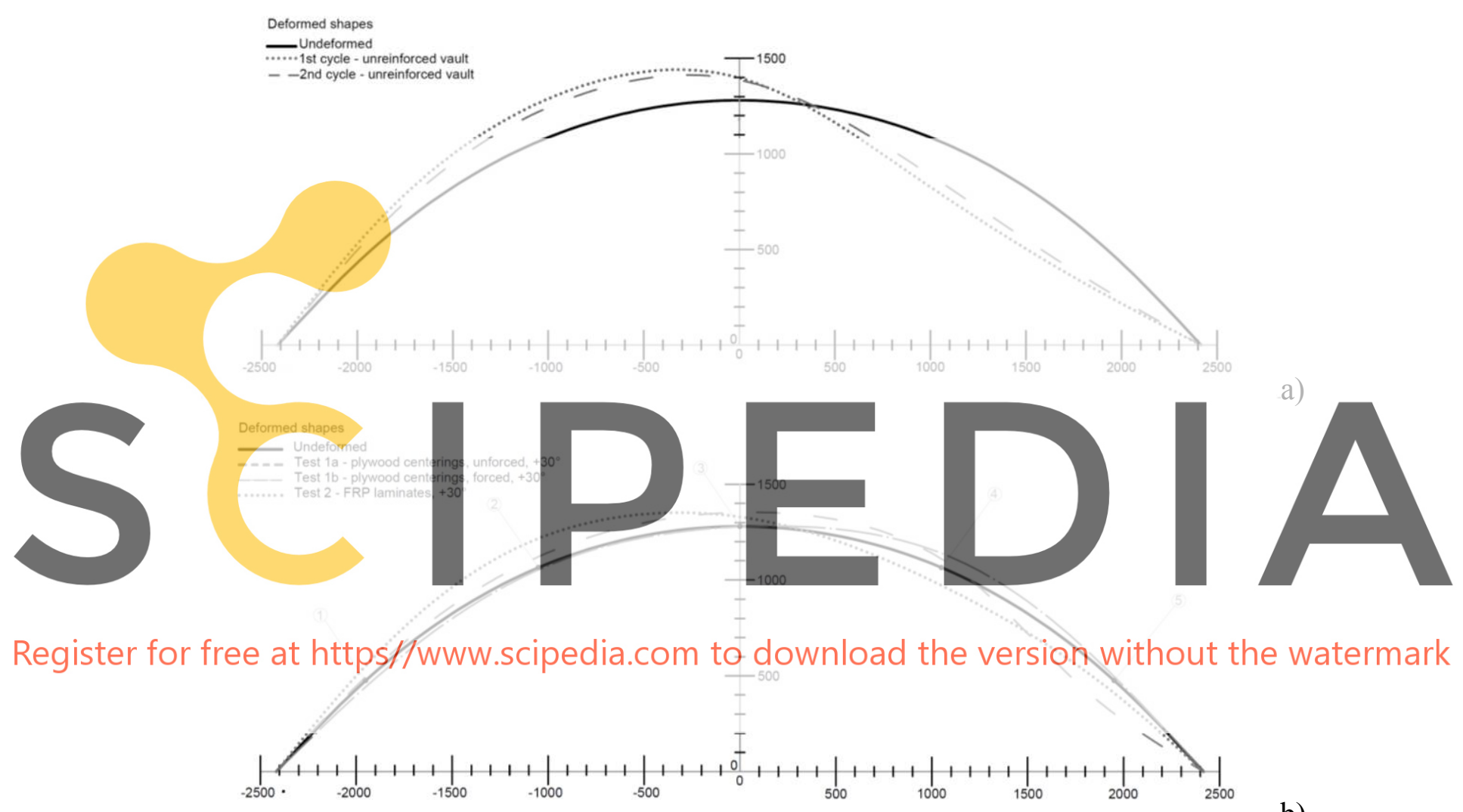

b)

Figure 10: Deformed shape of the unreinforced vault (a) and comparison of the deformed shapes of the vaults retrofitted with the three different strengthening solutions (b) for counter-clockwise rotation of $30^{\circ}$

\section{CONCLUDING REMARKS}

In this paper the seismic strengthening of barrel single-leaf masonry vaults with large span to thickness ratios, lacking lunettes and backfill material, is addressed. Such a typology is quite frequently found in churches, where single leaf vaults cover the main naves. The three major failure mechanisms of single leaf vaults subjected to earthquake were addressed, and focus was made on the strengthening against direct differential bending, which was acknowledged as the mechanism that cannot be inhibited by means of global seismic retrofit techniques (such as perimeter ties and roof or floor diaphragms) but rather requires specific strengthening of the vault. In particular, focus was made on vaults with large span-to-thickness ratios. 
An overview of possible strengthening techniques against direct bending mechanism was presented, and two different extrados solutions were proposed and tested: lightweight plywood restraining elements and FRP laminates embedded in a lime mortar layer.

Plywood centerings apply passive confinement to the vault extrados. The reinforcement is designed as a 3-hinged arch to allow accommodating possible small relative displacements of the vault springing, which may follow the deformation of internal ties or roof box structure. The solution may be conceived as passive or slightly active, in the latter case wooden wedges are forced along the vault-to-centering interface. FRP strengthening consists in embedding a carbon fiber grid into an inorganic pozzolanic lime mortar matrix.

The effectiveness of the retrofit techniques was verified through experimental tests on single-leaf barrel vault stripes at 1:2 scale, subjected to cyclic distributed unsymmetrical loads and through comparison with the seismic response of a reference unreinforced vault.

Lightweight plywood centerings were shown to inhibit the onset of the typical four-hinges failure mechanism. This lightweight, dry solution can be easily prefabricated, transferred and assembled at the construction site. The technique is reversible and fully compliant with the major preservation principles. FRP is also effective against the onset of the failure mechanism but entails larger deformations of the retrofitted vault, which may be detrimental in the case of possible decorations. The solution requires special man labor to ensure correct smoothening and cleaning of the vault extrados and to trigger effective bond between the mortar and the vault extrados. Both solutions are shown to enable small relative displacements of the vault springing, which may follow the deformation of possible internal ties.

Acknowledgements. This work was partly financed and developed within the research project DPC-ReLUIS 2014-2016 - Research line n.1. The authors thankfully acknowledge Marco Leali and Federico Carollo for carrying out the experimental tests and express their appreciation to the technical staff of the Structural Testing Facility at the University of Brescia for their assistance in the test program.

\section{REFERENCES}

[1] Gulli, R., 1993, Le volte in folio portanti: tecnica costruttiva ed impiego nell'edilizia storica e moderna", in: Proceedings of " $I^{\circ}$ Convegno Nazionale Manutenzione e Recupero nella città storica”, Rome. ARCO.

[2] Gulli, R. \& Mochi G., 1995, "Bóvedas tabicadas: architettura e construzione", in: "Il modo di costruire", CDP editrice.

[3] Ochsendorf, J. \& Freeman, M. (photographs), 2010, "Guastavino vaulting: the art of structural tile", New York: Princeton Architectural Press.

[4] Heyman, 1966, "The stone skeleton", International Journal of Solids and Structures 2, 249-279.

[5] O'Dwyer, D., 1999, "Funicular analyses of masonry vaults”, Computer \& Structures, 73: 187-197.

[6] Ramage, M., Ochsendorf, J., Block, P. \& Rich, P., 2008, "Advanced Geometry, Rudimentary Construction: Structural Form Finding for Unreinforced Thin-shell Masonry Vaults" in Advances in Architectural Geometry 2008, Vienna, Austria

[7] Block, P., DeJong, M. \& Ochsendorf, J., 2006, “As hangs the flexible line: Equilibrium of masonry arches". The Nexus Network Journal 8 (2), pp. 13-24.

[8] D'Ayala, D. and Tomasoni, E. 2008. The structural behaviour of masonry vaults: Limit state analysis with finite friction. Proceedings of the VI International Conference on Structural Analysis of Historical Constructions SAHC. 2-4 July, Bath, England. pp. 47-71. Ed. Taylor and Francis, London, UK. 
[9] Giuriani, E. \& Marini, A., 2008 "Experiences from the Northern Italy 2004 earthquake: vulnerability assessment and strengthening of historic churches", Proceedings of the VI International Conference on Structural Analysis of Historical Constructions SAHC. 2-4 July, Bath, England. pp. 13-24. Ed. Taylor and Francis, London, UK.

[10] Giuriani, E., Marini, A., Porteri, C. \& Preti, M., 2009 "Seismic vulnerability of churches associated to transverse arch rocking”, International Journal of Architectural Heritage, 3: 1-24, 2009. Ed. Taylor \& Francis Group, LLC.

[11] Giuriani, E. \& Marini, A., 2008, "Wooden roof box structure for the anti-seismic strengthening of historic buildings", Journal of Architectural Heritage: Conservation, Analysis and Restoration, Vol.2(3) pp. 226246.

[12] Ferrario, L., Marini, A., Riva, P. \& Giuriani, E., 2009, "Traditional and Innovative Techniques for the Seismic Strengthening of Barrel Vaulted Structures Subjected to Rocking of the Abutments", Proceedings of ATC-SEI Conference on Improving the Seismic Performance of Existing Buildings and Other Structures. San Francisco, California, December 9 -11.

[13] Ferrario, L., Marini, A., Riva, P. \& Giuriani, E., 2010, "Proportioning criteria for traditional and innovative Extrados techniques for the strengthening of barrel vaulted structures subjected to rocking of the abutments", Journal of Civil Engineering and Architecture, David Publishing Company, USA, pp.1-15. Vol. 4, N.5.

[14] Ferrario, L., Marchina, E., Marini., A., Preti, M. \& Giuriani, E., 2010, "Lightweight ribs for the strengthening of single-leaf vaults undergoing seismic actions", Proceedings of the VIII International Conference on Structural Analysis of Historical Constructions, Published in Advanced Materials Research, Vol.133-134, pp.923-928. Ed. Xianglin Gu and Xiaobin Song, China.

[15] Ferrario, L., 2013, "Masonry single-leaf barrel vaults: from the seismic vulnerability assessment to the proposal of an innovative retrofitting approach", $\mathrm{Ph} . \mathrm{D}$. Thesis, University of Brescia.

[16] Marini, A., Giuriani, E., Belleri, A., Preti, M., Ferrario, L., 2016, "Plywood extrados retaining structures for the retrofit of single leaf vaults", in: Proc. Of 16th International Brick and Block Masonry Conference "Masonry in a world of challenges", June 26 - 30, Padova, Italy

[17] Marini, A., Belleri, A., Preti, M., Riva, P., Giuriani, E., 2017, "Lightweight extrados restraining elements for the anti-seismic retrofit of single leaf vaults", Engineering Structures, 141, 543-554

[18] Tomasoni, E., 2008, "Le volte in muratura negli edifici storici, Tecniche costruttive e comportamento strutturale", Ph.D dissertation, University of Trento.

[19] Valluzzi, M., Valdemarca, M. \& Modena, C., 2001, "Behavior of Brick Masonry Vaults Strengthened by FRP Laminates." Journal on Composite Construction, 10.1061/(ASCE)1090-0268(2001)5:3(163), 163-169.

[20] Girardello, P., Pappas A., da porto F., Valluzzi, M.R., 2013, "Experimental testing and numerical modelling of masonry vaults". International Conference on Rehabilitation and Restoration of Structures, Chennai, 1316 February 2013

[21] Giamundo, V., Lignola, G. P., Maddaloni G., Da Porto, F., Prota, A., Manfredi, G., 2016, "Shaking table tests on a full-scale unreinforced and IMG retrofitted clay brick masonry barrel vault", Bull Earthquake Eng $14: 1663-1693$

[22] Giamundo V., Lignola G.P., Maddaloni G., Manfredi G., 2015, "Experimental investigation of the seismic performances of IMG reinforcement on curved masonry elements". Compos Part B, Eng 70:53-63. 